\title{
DIALOGISM AS A BASIC TEXT CATEGORY \\ AND ITS IMPLEMENTATION \\ IN THE ENGLISH SCIENTIFIC \\ AND TECHNICAL TEXTS
}

\author{
Anna Kostenko, \\ PhD in Philology, \\ Assistant Professor of the Department \\ of Theory and Practice of Translation, \\ Zaporizhzhia National Technical University, \\ Zaporizhzhia, Ukraine, \\ e-mail: annakostenko1971@gmail.com
}

Received March, 11, 2019; Accepted May, 29, 2019

\begin{abstract}
The article investigates dialogism as a category of English scientific and technical texts, ways and means of its interpretation. Being a communicative category, dialogism becomes an object of linguistic analysis due to the development of text communicative paradigm and discourse investigation. The topicality of the paper is determined by insufficient investigation of the category of dialogism in scientific and technical texts, its significance for their comprehension and interpretation, as well as by absence of works devoted to considering the ways and means of their interpretation. The article aims to identify units and means of rendering the abovementioned category in the process of dealing with English scientific and technical articles of electronics. The multi-dimensional, complex nature of dialogism is determined in a number of dialogic relationships: inter-subjective (between the author and the reader), interdisciplinary (between the author and other authors) and intrinsic (within the same text between its parts). Dialogism is an integral category of scientific and technical texts not only due to the purpose of their creation which consists in spreading certain scientific and technical information among specialists, but also in communicative intentions of these texts' authors by establishing contact with the addressee and attracting their attention to the most important information.
\end{abstract}

Key words: dialogism, text, discourse, scientific and technical texts, communicative category.

\section{Introduction}

The interest in communicative linguistics was underlined by studying communicative features and categories of the text. Despite the multiplicity of definitions given to the text by scholars, in most of them, the text is referred to as a written fixed speech opposed to verbal non-fixed speech. It was due to communicative linguistics development that the text became the largest communicative unit of writing-type speech, a dynamic product of thought-speech activity involved in communicative situations and processes. 
Despite the large number of linguistic papers devoted to the study of textbased categories, the issue of their construction and typology, the definition of dominant categories of the text, the investigation of their number and the hierarchy have remained open until now, and it is this fact that determines the article's topicality. This is due, first of all, to the fact that scholars belong to different linguistic schools and paradigms, and, consequently, to different viewpoints on the problem of text analysis.

One of communicative linguistics' tasks is to distinguish the concepts of "text" and "discourse." The plurality of definitions and interpretations of these concepts, approaches to their studies resulted in a controversial attitude to the commonality and discrepancy of these concepts, but most scholars are beginning to admit the communicative nature of both text and discourse. For example, L. Shen is sure that "text is the means of discourse, without which discourse would not be a linguistic activity" (Shen, 2012: 2667). Recognition of communicative basic characteristics of any text made it possible to review the nomenclature of text categories and expand them at the expense of communication.

Categories of the text determine its properties and features, thus making it possible to realize the nature and essence of the text as a coherent semantic and communicative phenomenon. The main categories of the text include textuality, informativeness, intentionality, coherence, cohesion, situationality, anthropocentricism. These categories are interconnected among each other.

The category of dialogism is also considered to be the basic text category which reveals its interactive, intertextual and intrinsic text character. Interactivity is determined by the addressability of the text, the relationship between its author and reader. Such interaction can be manifested both in dialogical and monologic speech directed by the author to the addressee. Consequently, dialogue is inherent not only in dialogical, but also in monologic texts. Dialogism as an intertextual category of text is manifested in its interaction with other texts while using citations, references, allusions, reminiscences from them. The intertextual character of dialogism reveals the interdependence of the text fragments, provides its structural and content cohesion as a semantic and communicative unit.

Dialogism is an integral category of scientific and technical texts not only due to the purpose of their creation which consists in spreading certain scientific and technical information among specialists, but also in communicative intentions of these texts' authors by establishing contact with the addressee and attracting their attention to the most important information. The methodological basis of the dialogic texts' analysis is the multi-dimensional, complex nature of dialogism itself determined by a number of dialogic relationships: inter-subjective (between the author and the reader), interdisciplinary (between the author and other authors) and intrinsic (within the same text between its parts). Due to M. Bakhtin's ideas, dialogism is both philosophy and methodology. This characteristic tries to give a different picture of the world and methodology to show us how we can make this world understood. At this stage of understanding, dialogism has a profound relationship with language and language is placed at the center of our understanding of the world of the "self" and the "other" (Manouchehri \& Zaki, 2012: 6). In other words, dialogism is a method or procedure, analysis, and interpretation to show the internal relations between ideas. 
Another methodological trend is connected with viewing multivoicedness and the multivoiced Self in the context of dialogic analysis. This trend reflects paradigmatic shifts in the social and psychological sciences away from individualistic and mechanistic epistemologies, toward more dynamic, anthropocentric, social alternatives that recognize the situated and intersubjective nature of meaning-making, and proves an insightful analysis of the voices within qualitative data is possible (Aveling, Gillespie and Cornish, 2015: 672). It is possible to suggest that the extent to which data are multivoiced (or 'monologic') depends not on the method used to collect them, but on the way the data are conceptualized and analyzed. However, no systematic bridge from conceptualization to analysis exists, which is a barrier to both the quantity and quality of future dialogical analyses.

From a number of different research approaches, it is obligatory to focus on various textual components: informativity, intentionality, connectivity, integrity, situationality. There should be a refreshing reassessment of the contrastive dimension in the study of voice and dialogic relations, taking into consideration language, specialized fields and genres.

\section{Text and Its Categories}

If in text-centric, non-communicative approaches to the text studies, its categories were defined as "interconnected essential features of the text that reflect certain parts of the text general content in various linguistic, speech (composite) means" (Zvegintsev, 1980: 13), then within the communicative approach, the category of the text is already considered as "specific features of the whole speech that distinguishes this whole (text) from other language phenomena" (Kamenskaya, 1990: 13). In T. Dridze's opinion, the text is simultaneously a "complex sign and integral unit of communication," and the text categories are actually a certain system of text dominant features "united into a single closed hierarchical communicative and cognitive structure based on the general concept or idea of the subjects' communication" (Dridze, 1996: 149). Consequently, any category of text is now considered by linguists as one of the interrelated essential features of its communicative system. The text categories are universal in their essence and are found in any text regardless of the language in which the text was created and the text type.

In the scientific linguistic literature, there is also the identification of textual and semantic-stylistic (functional-stylistic) categories that define the content and stylistic peculiarities of a particular text, its attribution to a certain functional style. In this connection, functional semantic-stylistic categories are often identified with the text and combine the system of language means of different levels used by the author for a certain communicative purpose. According to the linguists, these categories do not reveal the language systemic nature of the text, do not determine its interactive space, and although they have a certain communicative purpose, they are typical only of certain stylistic types of texts (Kozhina, Duskayeva and Salimovskyi, 2008: 51).

The category of textuality is the basic text category, the understanding of which allows reconsidering its nature and essence, structural-syntactic, semantic-meaningful, and communicative-pragmatic organization in the unity of all its components. Textuality is a synthesized phenomenon, in fact, a set of parameters, which tell the text 
from non-text. Each parameter is a complex phenomenon, interconnected in its implementation with other parameters. In domestic linguistics, these parameters are often referred to as the text categories that define the conceptual features of the text.

The category of textuality and the classical set of its parameters were identified by R. Beaugrande and W. Dressler in 1981. Although the concept of textuality itself and a set of its parameters (text categories) are constantly updated, the main ones include informativity, intentionality, connectivity, integrity, situationality (Beaugrande \& Dressler, 1981: 31-33).

The category of informativeness is associated with the text informative side. For example, I. Galperin distinguishes the following types of information that the text contains: content-fact, content-concept, content-subtext. The scientist notes that “... content-factual information contains reports of facts, events, phenomena described in the text. The content-conceptual information allows the addressee to understand the individual and author's perception of the relationship between the facts described by means of content-factual information, understanding their causal relationships ... Content-conceptual information is the intention of the author plus its meaningful interpretation" (Galperin, 2006: 27-28). The content-sensitive information reveals the hidden content of the text.

Intentionality determines the intention of creating the text by the author for a specific purpose (for example, to inform, to inquire, to describe, etc.) (Kamenskaya, 1990: 27). Taking into account connectivity as a textual category, scholars emphasize that communicative elements of the text must always be interconnected. In addition, the characteristic feature of each text is not only the content unity, but also, the so-called formal, external link between the individual parts of the text, ensuring its logical sequence, the interdependence of individual messages, facts, events, etc. In this connection, the following types of connection are distinguished, such as coherence and cohesion. Coherence is a semantic type of text communication that outlines the text content as a unit of communication (Kubryakova, 2001: 74). Cohesion is a special type of connections (graphic, lexical, grammatical, etc.) that provide a logical sequence, interdependence of the text continuum (Kubryakova, 2001: 75).

Integrity is a text category that reproduces the relative closeness of a text sign system, provided by the integration of all its levels and content, the perception of the text as a whole (Kubryakova, 2001: 76). Integrity manifests itself in specifying the author's plan, which appears in the text itself and finds its expression in it (Kubryakova, 2001: 77). The text from this point of view is intended to implement the author's plan.

A compulsory condition of integrity is situationality that distinguishes the text from any other meaningful communicative unit. Separate sentences, even if they are interconnected, can become the text only in a certain communicative situation. Scientific linguistic literature also distinguishes many other text categories, for example: intertextuality, accessibility, emotivity, modality, etc. (Kukharenko, 1988: 19-20; Novikov, 1983: 112). All categories of the text are combined with one common purpose - to realize the communicative intention of the author of the text and decode his intention in the process of communicative activity.

Researchers of the text also define one more category of a text, that is, anthropocentrism. Today anthropocentrism is one of the leading methodological principles of the language studies and language communication, according to which 
the above mentioned is considered as one of human activity types designed to meet people's needs, to be the mediator, while language is a means of preserving and transferring experience, knowledge, information. Although anthropocentrism was introduced by ancient philosophers who considered man as a "measure of all things," anthropocentrism owes its appearance in linguistics to the linguistic concept of W. Humboldt who believed that it was impossible to study a person without a language, and a language without a person. Since the text is a product of language activity created by man and for man, the anthropocentricity of the text is obvious.

The specified text category is versatile and complicated. Addressability as a text category is presented in the author's image and reflects the author's intentions implied in the text and aimed at the reader. As L. Aznabayeva notes, addressability "is not only an informative parameter of speech (speech designed for the listener); it also influences the form of speech by forcing the speaker to consider social, educational, professional, personal and other parameters of the addressee, his/her psychophysical state and attitude to the speaker" (Aznabayeva, 1999: 14). All the linguistic means and ways of expression implemented in the text may differ in certain texts of different types and genres, but they always point to the author's plan, determine its peculiarities, and reveal the author's position in one way or another.

Targeting information to the addressee, triggering his reactions by the author has a categorical nature, which determines the isolation of the universal text category addressability/addressivity. The specified text category is represented by the program of potential reader targeting orientation, which promotes understanding and correct interpretation of the text. O. Kamenskaya confirms this: "Considering the addressee, the author is concerned about the text organization, the use of such explicit and implicit markers that will allow the most optimal and most effective way for this text to be accepted by the addressee, focusing on the most important and relevant information" (Kamenskaya, 1990: 24). Orientation to the addressee, embodied in the category of addressability, also implies scheming the addressee' reactions by the author. It becomes clear from the above that the targeting orientation category is expressed not only in the peculiarities of the text content organization, but also involves taking into account social, professional, personal and other characteristics of the addressee.

Addressability is actually a communicative category of a text. This can be seen in N. Arutyunova uses the term "addressee" while emphasizing simultaneously the conscious aiming of any text or statement at a person (specific or non-specific one), which can be described in some way, with the communicative intention of the author that always agrees with this description, and the category of addressability itself is communicative (Arutyunova, 1981: 357-358).

The study of addressability as a communicative category of the text begins with spreading the communicative linguistics within which the text is studied as a unit of communication, included in a certain communicative situation that occurs between its participants. The text is also considered as a significant mediator between the author and the reader, and the category of text addressability is a reflection of its own dialogism. 


\section{Dialogism as a communicative category of the text}

The dialogic category of the text is not new to modern linguistics. The term

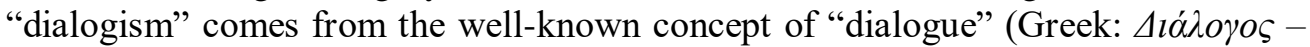
conversation) - the form of oral or written exchange of expressions, the specific form and organization of communication. At Socrates' times, dialogical speaking began to be studied in details. And since the sixteenth century dialogism began to be discussed as a reflection of the social content of human consciousness and human activity.

It is believed that the principle of dialogism was introduced in linguistics by W. von Humboldt in the XVIII century. Emphasizing the creative nature of the language, the scientist said that it was not so much a product of activity (ergon), but the very activity (energeia), the continuous process of content generating. In order to carry out such an activity, man needs someone else, communication and interaction with whom determine its dialogical nature.

Undoubtedly, dialogue is one of the most natural forms of dialogism reflection. However, dialogism is also considered to be a categorical feature of monologue speaking in any text. Consideration of the text in the dialogical aspect is associated with the name of M. Bakhtin whose theory about the targeting of any text, on the one hand, appears to be aiming at the addressee, and on the other hand, can be a response, peculiar reaction to the previous texts. Firstly, M. Bakhtin uses the term in its most ordinary sense to refer to a verbal interaction between two individuals. Here, the term "dialogic interaction" refers to the process of an utterance directed towards the other for a response. Three elements that are necessary for a dialogue become important in this context: the existence of two entities, the self and the other; the use of a language to convey an experience; and the relationship that develops between the two as a result of their interaction. Dialogue, in the second sense, is used as a metaphor to refer to the inter- and intra-orientation of a word with other words uttered or written. Owing to the interaction of the word with other alien words in the discourse, this orientation of the word leads to a conflictual condition, a "tension-filled environment" (Kumar, 2015: 14).

While studying the dialogue and the category of dialogism, M. Bakhtin made an important conclusion that the internal dialogism revealed in such interaction is inherent in purely monologue works. In this regard, M. Bakhtin remarked that "the event of the text life ... always develops on the verge of two consciousnesses: the consciousness of the author and the one of the reader" (Bakhtin, 1986: 112). According to M. Bakhtin, collision with the text, the penetration into it, is already a dialogue between the author and the reader (Bakhtin, 1986: 114). Starting the dialogue with the text itself and with its author, the reader joins the informative, semantic, and pragmatic levels of the text, creating the corresponding reaction, and in this case the interaction between the reader and the author, as well as the dialogic nature of the text, can be seen.

Noteworthy that in the enlarged sense the most general terms such as "dialogue" and "dialogism" are used in M. Bakhtin's scientific works without a certain terminological particularity meaning speaking aimed at the reader. The term "dialogism" was used after the publication of M. Hallquist's monograph "Dialogism: Bakhtin and His World," where dialogism is referred to as the dialogical philosophy of language and the methodology of human knowledge. In the methodology of text and speech research, the notion of the dialogic principle was introduced by 
Ts. Todorov in the monograph devoted to M. Bakhtin's theory. It is after this monograph that the following phrases, such as dialogic philosophy, dialogic theory, dialogical analysis, dialogical paradigm, dialogical discourse, dialogical method, dialogic interaction, dialogic communication, dialogical representation, dialogical culture, etc. penetrated into the scientific circle of humanitarian disciplines.

As a general approach and strict methodology, the dialogic principle is used in literary criticism studies, discourse and text analysis. Individual scientists also use the term "dialogism" in the enlarged sense is, on the one hand, a kind of dialogical philosophy and methodology of humanitarian knowledge, and on the other - the general principle of communicative human activity. Dialogism is a multifaceted complex category, actually a macro category which determines accurate text understanding. In this regard, it is considered as a set of several dialogic relations: intersubjective (between the author and the reader), interdisciplinary (between the author and other authors) and intertextual (within one text between its parts). By intersubjective dialogism, M. Kozhina means elements that are consciously emphasized by the author due to their special significance for the reader's adequate understanding of the text idea; by elements of interdisciplinary (intertextual) dialogism she means different types of intertexts included into the structure of the text: quotes, allusions, reminiscences; within the intertextual dialogism she considers near text elements (epigraphs, forewords, comments) that create the system of the author's comment and represent "tags of the text interpretation program, determining it more or less explicitly" (Kozhina, 1981: 79-81).

The category of intertextuality also acts as one of those text categories, which ensures the implementation of dialogism in a particular text. The question of intertextuality becomes the object of research of J. Kristeva, M. Bakhtin, R. Barthes, U. Eco, and others. The term "intertextuality" itself was introduced by J. Kristeva, M. Bakhtin's follower in her paper "Word, Dialogue and Novel" (Kristeva, 1986). She developed the theory of intertextuality from the reader's position. Thanks to J. Kristeva's works, intertextuality began to be understood, first of all, as a special principle of quoting previous texts in a new artistic context. It is through the prism of intertextuality that the world becomes a huge text in which everything has already been said and where the scientific world and various branches of knowledge are interlinked. Intertextuality is considered by scholars a recursive connection with certain texts (Dronova, 2006: 12), as well as the immersion of the text into the continuum of other texts, into the text tradition (Solodub, 2000: 52). Intertextuality helps perceive the text from the point of view of its dependence on other relevant texts. Consequently, the category of intertextuality emphasizes the openness of the text, its connection with others, and with the cultural context in general.

Quotes, allusions (Latin alludo - hints) are the display of intertextuality in the text that enriches text information by creating numerous associations at the expense of implied facts, events, etc. There are also reminiscences (Latin reminiscentia recollection) that involve introducing fragments in a certain text that remind the recipient of certain information. That is why the means of implementing intertextual connections are often used to influence the addressee of the text. In general there are about ten functions and techniques in the linguistic literature that can implement intertextuality of various levels: an implicit means of evaluation, a means of the addressee conviction, an original means of idea input, a creative contact means, an interpretive means, and etc. The set of intertextuality means is often marked with 
quote marks, footnotes, references, etc. Intertextuality is the basis for certain genres of the text, for example: parody, exposition, commentary, review, report, synopsis, etc. The integration of various types of texts into another text is also considered a display of intertextuality.

The connection between the categories of dialogism, addressability and addressivity is evident, since the dialogism of the text is based on the fact that each text contains the identities of the author and the addressee that interact by directing the author's intentions and ideas to the addressee. The task of the latter is to decode such plans. The cognitive basis of such interaction is a certain community of consciousness spheres of the addresser and the addressee: their thesauri, linguistic, communicative, linguistic, and cultural competence, mechanisms of association.

The category of intertextuality, which is considered by many linguists as a means of implementing the category (macrocategory) of dialogism, is referred to as one of the communicative categories of the text, since the text intertextuality, means of its implementation in the text itself, send the recipient to other texts, giving an opportunity to establish connections with them in order to understand the text deeper. There is no doubt that the category of dialogism, along with the categories of addressability and addressivity, also determines the communicative peculiarities of particular texts, their role in the process and the vector of communication: from the addresser to the addressee, from the author of the text to the reader.

\section{Implementing dialogism in the English scientific and technical texts}

It is believed that scientific and technical texts belong, first of all, to the realm of scientific communication. The success of scientific communication is associated with implementing the author's intentions that consists in helping the addressee become aware of the results of scientific and practical activities; deepening his/her special background knowledge; building the contact with the addressee and getting $\mathrm{him} / \mathrm{her}$ interested in the information provided; persuading the addressee in the authenticity of the message. Consequently, scientific and technical texts become not only means of exchanging information between specialists of a particular field of science and technology, but also means of sharing experience, exchanging thoughts and views, creating scientific and practical considerations.

Dialogism as the basic communicative category can be seen in scientific and technical texts most clearly, since the scientific problem of a particular field of knowledge can be formalized with creative interaction between different schools, approaches, concepts, and in scientists' verbal interaction explicated through texts and in the process of communication. Communication in the scientific and technical circles is professionally oriented, as it occurs, first of all, between specialists of a certain subject area. The variety of subject areas of scientific and technical communication determines the need to solve the problem of scientific and technical texts diversification.

Although the exchange of scientific and technical information can occur by means of oral speech (for example, reports, discussions, disputes, lectures on scientific and technical issues), the main means of communication in the field of science and technology is the text itself - written fixed speech. Traditionally, by scientific and technical texts scholars mean texts that have such content features as: 
1) the transfer of scientific and theoretical positions; 2) scientific and technical information; 3) educational material. Scientific and technical texts include programs, reports, information on research results, experiments, etc. By scientific and technical texts linguists also mean a thematically, stylistically and semantically organized, logically structured and completed unity which is characterized by the widespread use of special terminological vocabulary and the complexity of grammatical and syntactic structures used in scientific and technical fields of application.

It should be noted that in linguistics, there is still no clear division of scientific and technical texts into actually scientific and technical, so they are considered as elements of the same paradigm. Along with verbal elements in scientific and technical texts, there are special sign systems, symbolic and table-graphic text components, and various technical drawings, which together form a solid text.

Depending on the functional purpose, the following varieties of scientific and technical texts are distinguished:

1) scientific and technical literature itself (books/monographs, articles, conferences, symposiums, lectures, or similar event papers, presentations);

2) educational scientific and technical literature (manuals, books, reference books, theses, dissertations);

3) popular scientific literature;

4) technical documents;

5) technical advertisements and patents (Bidnenko, 2014: 181).

The communicative characteristics of scientific and technical texts should be considered as their distinguishing criteria. According to such characteristics the following types of texts can be distinguished:

1) instructive texts (memoranda, instructions, manuals, various technical textbooks);

2) informative texts (reference literature, technical reports, scientific, experimental and production technical texts, newsletters, profiles, annual reports, production programs, scientific and experimental articles);

3 ) texts that regulate official and business relations in the field of scientific and technical communication: patent literature, standards, data-sheets, tenders.

Despite various criteria to distinguish and differentiate scientific and technical texts, the dominant communicative function of such texts is, first of all, informative, the ability to store and transmit information fixed in a verbal form. Informativity being a relative feature of the text characterizes not only the general accuracy of the text information, but also the content information, which was mastered by the addressee and whose interpretation corresponds to the author's communicative intention.

The communicative intention of scientific and technical texts' authors is to provide the addressee with the information that is necessary for his/her activity in a certain scientific or technical field. If, for example, the recipient can conduct a particular experiment or perform certain operations on the basis of the text, then it is believed that the author's communicative intention has been achieved. The characteristic features of the scientific and technical text as a written form of communication include the distant relationship between their author (addresser) and the addressee, the real possibility of repeated access to the content of the text expressed in words, optimized for visual perception and graphically fixed for external use. 
The primary genre of scientific and technical texts is a scientific and technical article, the purpose of which is to state and solve a particular scientific problem. Usually the length of the article is average; it has conventional structure, a system of links and output data. The scientific and technical article consists of three parts with the first part containing the title of the article, the author's name and surname, the summary, the keywords, that is, it is a brief synopsis. The second part is related to its content, in which the following blocks are distinguished: introduction, materials and methods of research, its results and conclusions. The body of the article can also include accurate mathematical calculations, digital data, tables, drawings, graphs, citations with bibliographic data, schemes, etc. The third part contains a variety of auxiliary aids, special pointers and attachments, a system of links and output data. Scientific and technical articles, as well as other types of scientific and technical texts, are characterized by objectivity, consistency, accuracy of the statement, which are also embodied through dialogism as their basic category.

Emphasizing that the category of dialogism is multifold in scientific and technical texts, as in any other, there are several types of dialogism or dialogic relations: internal dialogism connected with the category of addressability and the addressee of the text; external dialogism, which can be seen in the intertextual links of the scientific and technical text, as well as the intertextual dialogism formed by the elements of the author's commentary, which determines the connection between the additional information introduced by the author for a better understanding of the basic information.

The internal dialogism is primarily traditional for scientific and technical texts and is determined by the situation in which the addresser (the author of the scientific text), guided by the addressee (the reader), cannot start an open dialogue with him/her, but is forced to constantly appeal to his/her knowledge, intuition, understanding of what is going on. To some degree, it is a one-way dialogue which includes the author's speech only, fixed in the form of his/her text. The reaction of the other party, that is, the addressee of the scientific and technical text, is not reflected in the language, but inevitably implied in his/her mind. Hypothetically, in order to optimize the perception and understanding of the text, the author should take into account such a reaction and use it to develop the text.

In this regard, elements of the dialogue appear where the author sees in his/her addressee not a passive recipient, but an active dialogue partner, who participates in the comprehension of information. Quite often, appealing to the knowledge or experience of the addressee, the author of the scientific and technical text uses not only the so-called thesaurus vocabulary (terms, special vocabulary), but also conversational constructions like "as you know," "as it was mentioned." Phrases of this type create an atmosphere of real communication, prompting the recipient not only to perceive the information passively, but also to form their own opinion, which in the future can serve as the basis for a new publication.

The author of the scientific and technical text can also use the performative verbs, which is typical of the process of the real communication. Such verbs serve the purpose of expressing the author's "I", transferring his/her point of view and attitude to the aforementioned. First of all, sharing information about certain actions, the author of the scientific and technical text prompts the addressee to keep to the same logical chain, which he/she followed him/herself while generating the text. That is why the verbs "to give," "to describe," "to utilize," and many others are 
often used in such texts. In the scientific and technical text, such verbs clarify the author's point of view, other views s/he aims to shares, for example: "We assume that..." Using special verbs, the author can emphasize or determine the information to which the reader should pay attention. Linguistic units of different level, mostly words and phrases, can inform the recipient of the author's train of thoughts, and, on the other hand, serve the function of attracting his/her attention.

Interrogative sentences the purpose of which is to make the addressee pay more attention to certain information in order to understand or rethink are also means of implementing dialogism in technical texts. Language structures and idioms that determine the course of the material presentation, its composition, the shifts from one subject to another, as well as certain points of the content, linguistic units of different level that perform the function of specification, explanation, evaluation, etc. also belong to the same category.

Unlike a dialogue that is often chaotic, and the direction of which is difficult to predict, the structure of the scientific and technical text is more logical. At the level of pragmatics, the dialogism of the scientific and technical text is reflected in the fact that its author (authors) tries to explain their communicative intentions to the potential reader implicitly. As the narration proceeds they provide explanations if they are not sure the information is understandable for the addressee, for example: The number of different analog circuits so far devised is huge, especially because a 'circuit' can be defined as anything from a single component, to systems containing thousands of components (Sky, 2014).

When constructing a scientific and technical text, the author does not have an opportunity to split the whole text into separate parts similar to the dialogue cues. At a deep level of the text, such a division still occurs. As a rule, the author distinguishes separate fragments of the text that represent the completed thematic compositions with logical structuring. In linguistic terms, it is represented by phrases, like "In this paper we consider..." (a kind of the text beginning that informs the recipient of the main subject and purpose); "Based on the above approach, we carried out a systematic search for appropriate ranges of..." (a kind of summarizing the research done; the response to the results to which the author wants to receive a feedback from the addressee of the text).

It is known that for scientific style the use of emotional vocabulary is not typical. But even in scientific and technical texts one can distinguish some emotionally loaded elements that appeal to the mind of the addressee, inducing him/her to the arcane debates with the author of the text. Such elements of the scientific and technical texts can include the phrases showing the author's attitude to the information given, for example: "It is natural to assume that the particular device may consist of circuitry that has one or the other or a mix of the two types" (Sky, 2014). With the phrase it is natural to assume the author induces the reader to agree with his/her point of view, perceiving it as a matter of fact.

Despite presenting information neutrally, scientific and technical texts can use evaluative phrases. Their purpose is to report the author's evaluation of a particular phenomenon, process, etc., to show it from a subjective point of view, for example: "It is interesting that analog circuits are sometimes called linear circuits although many non-linear effects are used in analog circuits such as mixers, modulators, etc." (Sky, 2014). The illusion of generating the text and the process of its perception as well as the corresponding reaction which is a distinctive feature of the natural 
dialogue, , is created by such means as the use of grammatical forms of the present time, imperative mood and active voice, for example: "We note that these solutions are remarkably similar to those shown...". In the given example, the reader experiences a sense of creating/writing the text just before the moment of its perception in the present time, which, to some extent, can also be considered as a reflection of the dialogism of the scientific and technical text.

\section{Conclusion}

The linguists' interest in communicative linguistics resulted in studying communicative characteristics and categories of the text. Despite the multiplicity of definitions given to the text by scholars, most of them refer to the text as written fixed speech opposed to verbal non-fixed speech. It was thanks to communicative linguistics spreading that the text became the largest communicative unit of writingtype speech, a dynamic product of thought-speech activity, included in communicative situations and processes.

One of the tasks of communicative linguistics is to distinguish the terms of "text" and "discourse." The multitude of definitions and interpretations of these concepts, approaches to their study did not lead linguists to a unanimous opinion about the generality and differences of these phenomena, but most scholars began to determine the communicative nature of both text and discourse. Recognition of communicative basic characteristics of any text made it possible to review the nomenclature of text categories and expand them at the expense of communication.

Text categories define its properties and features, which makes it possible to realize the nature and essence of the text as a holistic sign and communicative phenomenon. The main categories of the text include textuality, informativeness, intentionality, connectivity, integrity, situationality, antropocentricity. These categories are interconnected with each other.

The category of dialogism is also considered the basic category of the text, which reveals its interactive, intertextual and intrinsic text character. Interactivity is determined by the addressability of the text, the interaction of its author and reader. Such interaction can be manifested both in dialogical and monologic speech, directed by the author to the addressee. Consequently, dialogue is inherent not only in dialogical, but also monologic texts. Dialogism as an intertextual category of text is manifested in its interaction with other texts, which occurs through the use of citations, references, allusions, reminiscences from them. The intertextual character of dialogism reveals the interdependence of the text fragments, provides its structural and content integrity as a sign and communicative unit.

Dialogism is an integral category of scientific and technical texts. This is due not only to the purpose of their creation, which consists in transferring certain scientific and technical information for specialists' needs, but also in underlining the authors' communicative intentions: to establish contact with the addressee, to attract their attention to the most important information, to inform, instruct the addressee, etc. The multi-dimensional, complex nature of dialogism determines its understanding as a set of several dialogic relationships: intersubjective (between the author and the reader), interdisciplinary (between the author and other authors) and intrinsical (within the same text between its parts). 
Thus, in scientific and technical texts, dialogism is represented by several types: internal dialogism associated with the category of addressability; external dialogism manifested in the intertextual links of the text; inner-text dialogue formed by the elements of the author's commentary and presented by the additional data introduced by the author for better understanding of the basic text information.

The research of the category of dialogism, as well as the features of its interpretation, is carried out on the basis of English-language scientific and technical articles of electronics, which has not been done so far by linguists because of this scientific and technical sphere's complexity, as well as because of the multidimensional nature of the very category of dialogism.

English-language articles in the field of electronics are addressed to specialists in the particular field of knowledge. Since the authors of such texts can not appeal to their addressees and start a direct dialogue with them, they use a number of linguistic means to attract the recipients to the indirect dialogue, share the necessary professional information with them, activate their attention, etc.

The means of implementing the internal dialogism of the English-language articles of electronics are terminological units denotating its specialized concepts. It is through these units that the exchange of professional information, the transfer of experience is achieved, thus forming the addressee's scientific and practical thinking. The internal dialogism of the texts is also highlighted through verbs indicating the peculiarities of information perception, the addressee's response, personal pronouns, inserted words and sentences, spoken words and expressions, rhetorical questions, with the help of which the authors appeal to the addressee, indicate, hint how to interpret the information, draw attention to the most important parts, specify them.

The external dialogism of the scientific and technical text is implemented by introducing the so-called "someone else's speech," that is, various types of citation. This allows considering scientific and technical texts as a reflection of the dialogue of ideas, the dialogue of the author with the previous generations, as well as with him/herself. Most frequently used means of dialogism in scientific and technical texts are direct quotes, indirect speech as a translation of someone else's thoughts, with which the author agrees or disagrees, imperatives as an appeal to the reader, the verbs of Present Tense and Active Voice.

The prospects for further research can be seen in analyzing the peculiarities of the interaction of different types of dialogue in the texts of English-language scientific and technical articles and ways of their rendering into Ukrainian.

\section{References}

Arutiunova, Nina. 1981. "Faktor adresata." Izvestiya Akademii Nauk SSSR. Seriya literatury i yazyka 40(4): 356-367.

Aveling, Emma-Louise and Gillespie, Alex and Cornish, Flora. 2015. "A qualitative method for analysing multivoicedness." Qualitative Research 15(6): 670-687.

Aznabayeva, Larisa. 1999. Printsipy rechevogo povedeniya adresata $v$ konventsionalnom obshchenii. Doctor's Diss. Moscow State Pedagogical Institute.

Bakhtin, Mikhail. 1986. Estetika slovesnogo tvorchestva. Moskva: Isskustvo. 
Beaugrande, Robert-Alain de and Dressler, Wolfgang Ulrich. 1981. Einfürung in die Textlinguistic. Tübingen: Max Niemeyer Verlag.

Bidnenko, Natalia. 2014. "The Language Peculiarities of Modern English Scientific and Technical Literature Style." Vysnik Dnipropetrovskogo universitetu imeni Alfreda Nobelya 2(8): 181-185.

Dridze, Tamara. 1996. "Sotsialnaya kommunikatsiya kak tekstovaya deyatelnost v semisotsiopsykhologii." http://ecsocman.hse.ru/data/931/005/1218/ 016_Dridze.pdf. Accessed 25 Feb. 2019.

Dronova, Yelena. 2006. Stilisticheskyi priyom allyuzii $v$ svete teorii intertekstualnosti (na materiale yazyka anglo-irlandskoy dramy pervoy poloviny XX veka). PhD Diss. Voronezh State University.

Galperin, Iliya. 2006. Tekst kak obyekt lingvisticheskogo issledovaniya. Moskva: Komkniga.

Kamenskaya, Olha. 1990. Tekst i kommunikatsiya. Moskva: Vysshaya shkola.

Kozhina, Margarita. 1981. "O dialogichnosti pismennoi nauchnoi rechi." Russkyi yazyk za rubezhom 6 :77-83.

Kozhina, Margarita and Duskayeva, Liliya and Salimovskyi, Vladimir. 2008. Stilistika russkogo yazyka. Moskva: Flinta.

Kristeva, Julia. 1986. "Word, Dialogue and Novel." Translated by Alice Jardine, Thomas Gore and Léon S. Roudiez. In The Kristeva Reader, edited by Toril Moi, 33-61. New York: Columbia University Press.

Kubryakova, Yelena. 2001. "O tekste i kriteriyakh yego opredeleniya." Tekst. Struktura i semantika 1: 72-81.

Kukharenko, Valeriya. 1988. Interpretatsiya teksta. Moskva: Prosveshcheniye.

Kumar, Amith. 2015. Bakhtin and Translation Studies: Theoretical Extensions and Connotations. Cambridge: Scholars Publishing.

Manouchehri, Abbas and Zaki, Gitti Pour. 2012. "An Analysis of Dialogism in Mikhail Bakhtin's Thought: Convergence of Philosophy and Methodology." International Journal of Political Science 2(4): 1-9.

Novikov, Anatoliy. 1983. Semantika teksta i yeyo formalizatsiya. Moskva: Nauka.

Sky, Ryu Gaiden. 2014. Tactical Shooter Pro Gaming "Performance” Guide, https://books.google.com.ua/books?id=Ny9fDAAAQBAJ\&printsec=frontcover\&dq =Tactical+Shooter+Pro+Gaming+Performance+Guide:+First+Person+Shooter+tacti

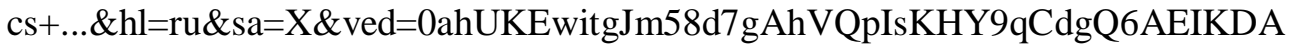
$\mathrm{A \# v}=$ onepage $\& \mathrm{q}=$ Tactical $\% 20$ Shooter $\% 20$ Pro\%20Gaming\% 20 Performance $\% 20 \mathrm{Gu}$ ide $\% 3$ A\% 20First $\% 20$ Person\%20Shooter\%20tactics $\% 20 \ldots \& \mathrm{f}=$ false. Accessed 28 Feb. 2019.

Shen, Lihong. 2012. "Context and Text." Theory and Practice in Language Studies 2(12): 2663-2669.

Solodub, Yuriy. 2000. "Intertekstualnost kak lingvisticheskaya problema." Filologicheskiye nauki 2: 51-57.

Zvegintsev, Vladimir. 1980. "O tselnooformlenosti yedinits teksta." Izvestiya Akademii Nauk SSSR. Seriya literatury i yazyka 39(1): 13-21. 